\title{
Foundationalism for Modest Infinitists
}

Forthcoming in The Canadian Journal of Philosophy

\author{
John Turri \\ Huron University College \\ john.turri@gmail.com
}

\begin{abstract}
Infinitists argue that their view outshines foundationalism because infinitism can, whereas foundationalism cannot, explain two of epistemic justification's crucial features: it comes in degrees and it can be complete. I present four different ways that foundationalists could make sense of those two features of justification, thereby undermining the case for infinitism.
\end{abstract}

\section{Introduction}

We find two main contemporary arguments for the infinitist theory of epistemic justification ('infinitism' for short): the regress argument (Klein 1999, 2005) and the features argument (Fantl 2003). I've addressed the former elsewhere (Turri 2009a). Here I address the latter.

Jeremy Fantl argues that infinitism outshines foundationalism because infinitism alone can explain two of epistemic justification's crucial features, namely, that it comes in degrees and can be complete. This paper demonstrates foundationalism's ample resources for explaining both features.

Section 2 clarifies the debate's key terms. Section 3 recounts how 
infinitism explains the two crucial features. Section 4 presents Fantl's argument that foundationalism cannot explain the two crucial features. Section 5 explains how foundationalism can explain the two crucial features. Section 6 sums up.

\section{Terms and Requirements}

Infinitism is the view that a proposition $Q$ is epistemically justified for you just in case there is available to you an infinite series of non-repeating reasons that favors believing Q (Fantl 2003, 539). ${ }^{1}$ Foundationalism is the view that $Q$ is epistemically justified for you just in case you have a series of non-repeating reasons that favors believing $\mathrm{Q}$, terminating in a properly basic foundational reason "that needs no further reason." 2

I cannot here fully characterize epistemic justification, partly because doing so would beg important questions in the present context, but I may say this much. Epistemic justification is the positive normative status needed for knowledge, closely associated with having evidence in favor of the truth of some claim, and typically contrasted with the practical justification, whether moral

Fantl $(2003,539-540)$ indicates that he is concerned with propositional, rather than doxastic, justification. The latter requires that the belief be properly held on the basis of the good reasons you possess; the former does not. Stated more fully, the infinitist theory of propositional justification is: The proposition $Q$ is propositionally justified for $S$ just in case there is available to $S$ at least one infinite series of propositions (or reasons) such that $R_{1}$ is a good (and undefeated) reason to believe $Q, R_{2}$ is a good (and undefeated) reason to believe $R_{1}, R_{3}$ is a good (and undefeated) reason to believe $R_{2}, \ldots, R_{m+1}$ is a good (and undefeated) reason to believe $R_{m}$, for an arbitrarily high $\mathrm{m}$. See Turri 2009b.

2 I doubt that this fully satisfactorily characterizes foundationalism, but I won't stop to argue the point here. It isn't fully satisfactory because foundationalism needn't require that the chain of reasons terminate. See Turri 2009a, $162-3$. 
or prudential, involved in action. ${ }^{3}$ I shall refer to it simply as 'justification'.

Doubtless justification comes in degrees. You can obviously be more or less justified in accepting some claim. An adequate theory of justification must respect this, and "explain why or show how" justification comes in degrees. Call this the degree requirement.

Complete justification is "justification for which there is no higher degree" (Fantl 2003, 538), or otherwise put, "that degree of justification that cannot be increased further" (Fantl 2003, 547). This contrasts with adequate justification, which is the minimal degree of justification required for knowledge. It is not plausible to identify adequate justification with complete justification. That justification can be complete is less obvious than that it comes in degrees. For the sake of argument, I grant that justification can be complete. As such, an adequate theory of justification must likewise explain why or show how justification can be complete. Call this the completeness requirement.

\section{How Infinitism Proposes to Meet the Requirements}

Infinitists satisfy the degree requirement by pointing out that length comes in degrees, which justification may mirror. "All else being equal, the longer your series of reasons for a proposition, the more justified it is for you" (Fantl 2003, 554).

Fantl offers the following analysis of complete justification: Q is completely justified for you just in case you have an infinite array of adequate reasons for Q (Fantl 2003, 558). Having an infin-

3 Though see Fantl and McGrath 2002 and 2007 for more on the complex relationship between epistemic and practical matters. 
ite array involves infinitely more than merely having an infinite series. To have an infinite array of reasons favoring $Q$, for each potential challenge to $\mathrm{Q}$, or to any of the infinite reasons in the chain supporting Q, or to any of the inferences involved in traversing any link in the chain, you must have available a further infinite series of reasons. In a word, it requires having an infinite number of infinite chains.

This analysis of complete justification ensures that no proposition is ever completely justified for any of us. Fantl does not view this as a problem, because he intuits that although many propositions are adequately justified for us, none is completely justified.

There is an alternative view, however. It seems that we are justified in being absolutely certain of some claims. For example, I know for absolute certain that I exist, and that something exists. Furthermore, it is natural to suppose that we are completely justified when we know for absolute certain. So at least some claims would seem to be completely justified for us. If correct, this confounds Fantl's infinitist analysis of complete justification. However, the following discussion does not presuppose that it is correct.

\section{How Foundationalism Supposedly Fails to Meet the Requirements}

Foundationalists divide over how to understand foundational reasons. Traditional foundationalists contend that foundational reasons are "self-justifying" because their mere truth suffices to justify them. The claims $<$ I am thinking $>$ and $<$ There is at least one proposition that is not both true and false $>$ are plausible candidates for self-justifying reasons. Metajustificatory foundationalists deny that the mere truth of a founda- 
tional reason ensures its foundational status. Instead, they say, foundational reasons must have property F. Different theorists adopt different values for 'F'. Some say it is 'is reliably caused', others say it is 'coheres with the subjects other beliefs', others say it is 'is clearly and distinctly perceived', and yet others might say it is 'is approved by society' or 'is approved by God'. Other values are possible. Importantly, metajustificatory foundationalism "cannot require that a believer have access to the metajustificatory feature as a reason for the foundational reason," because that would rob the putative foundational reason of its status as foundational (Fantl 2003, 541). It would effectively require a further reason for the reason that supposedly stood in no need of it.

Fantl's division may not capture every important distinction among varieties of foundationalism. But it does divide all foundationalists into two neat groups, and this suffices for his purposes. We may represent his basic argument as follows:

1. All foundationalist theories are either traditional or metajustificatory. ${ }^{4}$ (Premise)

2. Traditional foundationalism cannot satisfy the degree requirement. (Premise)

3. Metajustificatory foundationalism cannot satisfy the completeness requirement. (Premise)

4. Therefore no foundationalist theory can satisfy both the degree and completeness requirements. (From 1-3)

5. An adequate theory of justification must satisfy both the degree and completeness requirements. (Premise)

6. Therefore no foundationalist theory of justification is adequate. (From $4-5$ )

The argument is valid, so it remains to ask whether the premises

4 The 'or' here should be understood exclusively. 
are true. I am granting premises 1 and 5 for the sake of argument. This leaves 2 and 3. The remainder of this section presents Fantl's case for each.

We begin with Fantl's case for 2, i.e. against traditional foundationalism. Traditional foundationalism has insufficient resources to satisfy the degree requirement. All self-justifying reasons are by definition true, and their truth justifies them. Yet "truth per se cannot determine which self-justifying reasons are more or less self-justifying" (Fantl 2003, 544). Appealing to properties other than the truth of foundational beliefs is inconsistent with traditional foundationalism; it would effectively transform it into a form of metajustificatory foundationalism. So truth alone won't suffice, and no other property is eligible. Traditional foundationalism cannot satisfy the degree requirement.

We now move on to Fantl's case for 3, i.e. against metajustificatory foundationalism. To satisfy the completeness requirement, the metajustificatory foundationalist will have to say something like this:

$\mathrm{Q}$ is completely justified for you iff you have a non-repeating series of reasons for Q, ultimately founded on a reason that exemplifies the metajustificatory feature $[\mathrm{F}]$ to the highest possible degree. (Fantl 2003, 546)

But the proposal fails. No matter what value ' $F$ ' takes, if you gain a reason to think that the foundational reason completely exemplifies $\mathrm{F}$, and that exemplifying $\mathrm{F}$ is epistemically important, then Q will thereby become better justified for you. Consider, for example, a reliabilist version of metajustificatory foundationalism, which says that $\mathrm{Q}$ is completely justified for you just in case 
you have a non-repeating series of reasons for Q, ultimately founded on a $100 \%$ reliable reason. If you gain a reason to believe that your foundational reason was 100\% reliably caused, and that reliability is epistemically important, then $\mathrm{Q}$ will thereby become better justified for you. ${ }^{5}$ But then metajustificatory foundationalism has not satisfied the completeness requirement, for it will be possible to increase your justification for $\mathrm{Q}$ beyond what maximal exemplification of $\mathrm{F}$ would allow.

\section{Foundationalist Solutions}

I begin by responding to 2. The simplest response is to endorse the view, familiar from fuzzy logic, that truth comes in degrees (see Priest 2001, chapter 11). On this view, we may represent a proposition's degree of truth by assigning it a real number in the interval between 0 and 1 , inclusive (represented by '[o, 1]'). The degree of justification could then covary with the foundational reason's degree of truth. Complete justification would correspond to a foundational reason true to degree 1. A traditional foundationalist may, if she likes, treat 1 as an ideal limit that is never actually reached.

A second response suggests itself. Retain a standard non-degreed theory of truth. A foundational reason's truth suffices to render it adequately justified for you; it is in this sense that a foundational reason's truth suffices to justify it. However, any degree of justification beyond adequate requires that you be aware of the foundational reason's truth. Awareness comes in degrees.

5 Fantl $(2003,540$ n.7) says that reasons are propositions. Yet it makes no sense to talk about a proposition being reliably caused. We must, I believe, understand this to mean a reliably caused token belief state, which takes the foundational proposition as its object. 
Complete justification requires perfect awareness of the foundational reason's truth. Should we desire, we may represent the degree of awareness by assigning it a real number in the interval [o, 1]. Again, the traditional foundationalist may treat perfect awareness as an ideal limit that is never actually reached.

I shall now respond to 3 . One response is to adopt a two-dimensional model of belief. The first dimension is credence, or how strongly you believe. Credence comes in degrees, which we may represent by real numbers in the interval [o, 1]. 1 represents full belief, o full disbelief, and .5 perfect suspension of judgment. The second dimension is fixation. At any point in time, you can be more or less fixated on a certain degree of credence, i.e. it could more or less easily turn out that your credence shifts from where it is to some other point in the interval. Fixation likewise comes in degrees, which we may also represent by real numbers in the interval $[0,1]$, with 0 indicating the maximum level of volatility consistent with the state in question being a belief, and 1 the maximum level of imperviousness to change consistent with the state in question being a belief. We can plot these two dimensions on a graph, the $\mathrm{y}$-axis representing credence and the $\mathrm{x}$-axis representing fixation.

With this framework in place, a metajustificatory foundationalist could say that having a non-repeating series of reasons for $\mathrm{Q}$, ultimately founded on a reason that fully exemplifies the metajustificatory property F, justifies full belief in Q. That is, it justifies you in being here (represented by the star) on your belief-graph for Q: 


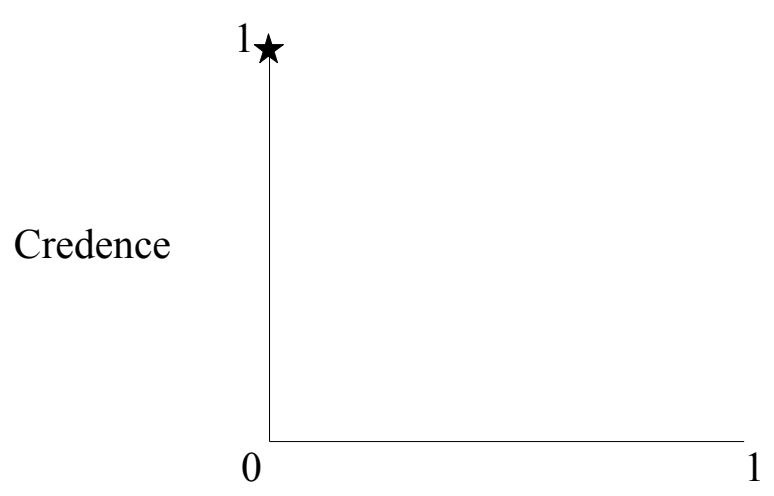

Fixation

Gaining a reason to believe the proposition $<$ Full belief in $Q$ is justified for me> increases the degree to which you are justified in being fixated in your full belief in Q. In other words, it justifies for you a greater degree of fixation, moving you further to the right along the $\mathrm{x}$-axis.

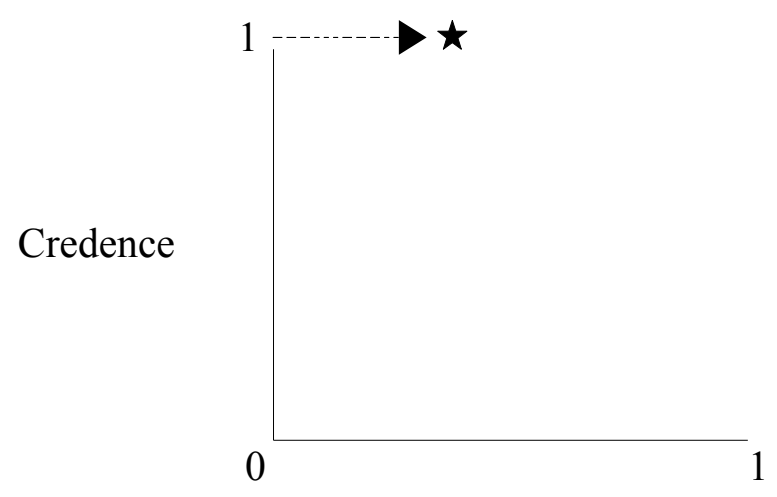

Fixation

Gaining a further reason to believe the proposition $<$ Full belief in < full belief in $\mathrm{Q}$ is justified for me> is justified for me> justifies an even greater degree of fixation in your full belief in $\mathrm{Q}$. Further iterations at higher levels are handled similarly. There is no limit in principle to the number of levels.

We are now positioned to offer the metajustificatory foundationalist proposal:

$\mathrm{Q}$ is completely justified for you just in case you are justified in being maximally fixated 
at full belief in Q.

The metajustificatory foundationalist may treat maximal fixation as the ideal limit, which can be approached to varying degrees but never actually reached.

A second response suggests itself. Set aside the two-dimensional model of belief, and adopt instead a qualitative commonsense framework for measuring strength of belief, with full belief being the strongest. $\mathrm{Q}$ is adequately justified for you when full belief in $\mathrm{Q}$ is justified. Adequate justification could be overdetermined. That is, you could have more than one reason, or chain of reasons, in virtue of which $\mathrm{Q}$ is adequately justified for you. One such reason could be the proposition $<$ Full belief in Q is justified for me $>{ }^{6}$ There is no limit in principle to the degree of overdetermination. Having recognized all this, the metajustificatory foundationalist could propose:

$\mathrm{Q}$ is completely justified for you just in case it is infinitely overdetermined that full belief in $\mathrm{Q}$ is justified for you. ${ }^{7}$

6 Here I rely on a principle that Fantl (2003: 549) himself relies on when arguing against metajustificatory foundationalism: "Your epistemic position can be improved in one of two ways: 1) the degree to which $p$ is justified for you can increase and 2) the degree to which it is justified for you that $p$ is justified for you can increase."

7 Note that accepting this doesn't require the metajustificatory foundationalist to reject the earlier claim, "if you gain a reason to think that the foundational reason completely exemplifies $F$, and that exemplifying $F$ is epistemically important, then $Q$ will thereby become better justified for you." For we can understand "better justified' to include not only an increase in the degree of justification, but an increase in the security or stability of the degree of justification, which overdetermination promotes. This remains true whether justification is determined by reliability or any other plausible candidate the metajustificatory foundationalist suggests. 


\section{Conclusion}

That brings my discussion to a close. We have seen four responses to Fantl's argument, two on behalf of both the traditional foundationalist and the metajustificatory foundationalist. If any of the four works, then foundationalism can indeed satisfy the twin requirements of degree and completeness, thereby undermining Fantl's case for infinitism. 


\section{References}

Fantl, Jeremy. 2003. "Modest Infinitism.” Canadian Journal of Philosophy 33 (2003): $537-562$.

Fantl, Jeremy and Matthew McGrath. 2002. "Evidence, Pragmatics, and Justification." The Philosophical Review 111 (2002): $67-94$.

Fantl, Jeremy and Matthew McGrath. 2007. "On Pragmatic Encroachment in Epistemology." Philosophy and Phenomenological Research 75 (2007): 558 - 589.

Klein, Peter. 1999. "Human Knowledge and the Infinite Regress of Reasons." Philosophical Perspectives 13 (1999): 297 325 .

Klein, Peter. 2005. "Infinitism Is the Solution to the Regress Problem." In Contemporary Debates in Epistemology, ed. Matthias Steup and Ernest Sosa. Malden, Mass.: Blackwell.

Priest, Graham. 2001. An Introduction to Non-Classical Logic. Cambridge: Cambridge University Press.

Turri, John. 2009a. "On the Regress Argument for Infinitism." Synthese 166 (2009): 157 - 163.

Turri, John. 2009b. "An Infinitist Account of Doxastic Justification." dialectica 63:2 (2009): $209-218$. 